
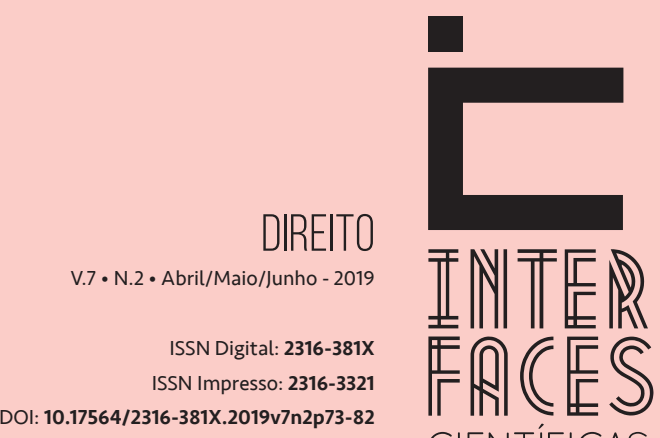

CIENTÍFICAS

\section{VENEZUELANOS NO BRASIL: DIREITOS DOS IMIGRANTES E A SAÚDE PÚBLICA LOCAL}

\author{
VENEZUELANS IN BRAZZL: \\ IMMIGRANT RIGHTS AND LOCAL PUBLIC HEALTH
}

\section{VENEZOLANOS EN BRASIL: DERECHOS DE LOS INMIGRANTES Y LA SALUD PÚBLICA LOCAL}

Jayrton Noleto de Macedo ${ }^{1}$ Osvaldo Vanderley de Sousa Júnior ${ }^{2}$

Helen Mariel Biazussi ${ }^{3}$

Bruno Gomes Pereira ${ }^{4}$

\section{RESUMO}

Esse artigo visa, informar as garantias dos imigrantes venezuelanos no Brasil. Buscou-se, abordar sobre a epidemia de sarampo e as consequências para a região de Roraima. Bem como, ressaltar a providência jurídica que o estado tomou perante essa situação. 0 sarampo é uma doença viral infectocontagiosa grave, transmitida por vias respiratórias, que acomete principalmente crianças desnutridas. 0 Brasil foi certificado como livre da doença no ano de 2016. Entretanto, no ano de 2018, devido ao intenso fluxo migratório na fronteira entre Brasil e Venezuela, no estado de Roraima, a doença ressurgiu, acometendo 79 pessoas, incluindo duas mortes de crianças. 0 estado protocolou no STF, um pedido afim de tentar impedir a entrada de imigrantes no Brasil. Porém, existe uma norma infraconstitucional que garante direitos aos imigrantes. $\mathrm{Na}$ saúde pública, os entes federativos em parcerias com organizações mundiais da saúde, iniciaram uma campanha de vacinação em massa da população da região em questão. A partir disso, foi possível observar que o Brasil se posicionou de forma exemplar ao cumprir com seus deveres perante aos imigrantes e a saúde pública de modo geral.

\section{PALAVRAS-CHAVE}

Sarampo; Roraima; Lei nº 13.445 


\section{ABSTRACT}

This article aims to inform as guarantee of the Venezuelan immigrants in Brazil. It was sought to address the measles epidemic and the consequences for the region of Roraima. As well as a legal provision requiring due attention to the situation. Measles is a serious infectious and contagious viral disease transmitted by the respiratory system, which mainly affects the malnourished. Brazil was certified as free of disease in 2016. However, in the year 2018, the resurgence of the disease, involving 79 people, including two deaths of children, was reported to the migrant population on the border between Brazil and Venezuela in the state of Roraima. . The state filed with the STF, at the request of refund of entry of immigrants in Brazil. However, there is an infra-constitutional norm that protects the rights of immigrants. In public health, federates in partnership with world health organizations have begun a campaign of mass vaccination of the population of the region in question. From this, it was possible to observe Brazil in order to fulfill its duties with immigration laws and public health in general.

\section{KEYWORDS}

Measles. Roraima. Law No. 13,445

\section{RESUMEN}

Este artículo pretende, informar las garantías de los inmigrantes venezolanos en Brasil. Se buscó, abordar sobre la epidemia de sarampión y las consecuencias para la región de Roraima. Así como, resaltar la providencia jurídica que el estado tomó ante esa situación. El sarampión es una enfermedad viral infectocontagiosa grave, transmitida por vías respiratorias, que afecta principalmente a niños desnutridos. En el año 2018, debido al intenso flujo migratorio en la frontera entre Brasil y Venezuela, en el estado de Roraima, la enfermedad resurgió, afectando a 79 personas, incluyendo dos muertes de niños. El estado protocoló en el STF, un pedido a fin de intentar impedir la entrada de inmigrantes en Brasil. Sin embargo, existe una norma infraconstitucional que garantiza derechos a los inmigrantes. En la salud pública, los entres federativos en alianzas con organizaciones mundiales de salud, iniciaron una campaña de vacunación masiva de la población de la región en cuestión. A partir de eso, fue posible observar que Brasil se posicionó de forma ejemplar al cumplir con sus deberes ante los inmigrantes y la salud pública de modo general.

\section{PALABRAS CLAVE}

Sarampión; Roraima; Ley nº 13.445 


\section{INTRODUÇ̧̃̃o}

O Estado de Roraima (RR) passa por uma situação delicada, ocasionada pela imigração de cidadãos venezuelanos. Tal fato se dá pela falta de recursos que este Estado necessita para recepcionar os imigrantes. Além disso, existe todo um procedimento inerente à saúde pública que deve ser observado, como forma de assegurar a integridade sanitária desses indivíduos. Como exemplo, podemos citar a atenção à vacinação desses imigrantes, visto que ao passar pela fronteira entre Venezuela e Brasil, não existe um controle de pessoas imunizadas.

A inobservância desses procedimentos resultou na ocorrência de vários casos de sarampo naquela região, estes, importados da Venezuela, visto que o Brasil, no ano de 2016, recebeu certificação da Organização Pan-Americana da Saúde (OPAS) e Organização Mundial da Saúde (OMS) de país livre do Sarampo.

Nesse sentido, é necessário problematizar os direitos dos imigrantes, procedimentos a serem adotados na área da saúde pública e a reação do estado mediante essa situação. Razões essas, pela qual se redige a presente pesquisa.

Assim, objetivou-se informar as garantias a serem atribuídas aos imigrantes venezuelanos, bem como, diferenciar os termos; emigrante, imigrante, visitante e refugiados. Ademais, buscou-se abordar sobre a erradicação do sarampo e as consequências de seu retorno para a saúde pública da região de Roraima. Por fim, analisou-se a reação de RR, frente a crise enfrentada.

\section{METODOLOGIA}

Será realizada uma revisão bibliográfica dos institutos legais, por meio de documentos oficiais, eletrônicos e impressos. Bem como, busca de literaturas que abordem os conceitos de sarampo, saúde pública, direitos inerentes aos imigrantes, entre outros.

Objetiva-se extrair dos mesmos, um embasamento técnico e profissional, que possibilite a análise de todo o caso, pelo profissional da área da saúde, além de um posicionamento jurídico e social. Também, será feito um levantamento qualitativo de periódicos, livros e notícias na mídia, a fim de esclarecer, discorrer e elucidar todos os objetivos propostos na presente pesquisa.

\section{LEI DE MIGRAÇÃO E CASOS DOS VENEZUELANOS NO BRASIL}

Diante dos inúmeros imigrantes venezuelanos que ingressam no território pátrio pela fronteira com o Estado de Roraima, vem surgindo uma série de fatores que estão comprometendo a integridade física e sanitária da população local, bem como as dos sujeitos imigrantes. É sabido que o Brasil enfrenta uma grande crise política e econômica, o que acaba agravando a situação já delicada da região fronteiriça de RR. 
Com a crise no Brasil, quase todos os estados e municípios da federação sofrem com a falta de emprego, escassez de recursos financeiros, falta de saúde de qualidade, segurança pública dentre outros problemas. A situação se amplia nas regiões como RR, uma vez que o poder público necessita de recursos para investir em garantias básicas aos populares nacionais e à comunidade estrangeira, que migra para aquela região.

Além das garantias constitucionais, que é atribuída ao povo brasileiro, devido ao quesito de cidadania jus soli (configura-se como cidadão quaisquer pessoas nascidas em território brasileiro), temos a lei que tutela os direitos dos estrangeiros que vêm residir em nosso país com animus definitivo.

Essa lei está disposta no sistema infraconstitucional, com o $n^{0}$ 13.445, de 24 de maio de 2017, ela dispõe principalmente, sobre os direitos e os deveres do migrante e do visitante, além de regular a sua entrada no Brasil, bem como estabelece princípios e diretrizes para as políticas públicas (BRASIL, 2018a).

Tal instituto legal, elucida que "pessoa nacional de outro país ou apátrida que trabalha ou reside e se estabelece temporária ou definitivamente no Brasil” é reconhecido como imigrante. Por conseguinte, emigrante se conceitua nessa mesma lei, como "brasileiro que se estabelece temporária ou definitivamente no exterior”. Por fim, vê-se nessa lei, que o visitante é “a pessoa nacional de outro país ou apátrida que vem ao Brasil para estadas de curta duração, sem pretensão de se estabelecer temporária ou definitivamente no território nacional” (BRASIL, 2018a).

Em sentido contrário, existe outra lei, tratando sobre o refugiado, sendo de número 9.474 de junho de 1997, dispondo em seu artigo $1^{\circ}$, inciso I, que refugiado é todo indivíduo que “devido a fundados temores de perseguição por motivo de raça, religião, nacionalidade, grupo social ou opiniões políticas encontra-se fora de seu país de nacionalidade e não possa ou não queira acolher-se à proteção de tal país" (BRASIL, 2018b).

Assim, observa-se que os cidadãos venezuelanos que ingressam em território brasileiro, estão na condição de imigrantes, conforme o tipificado na Lei 13.445/17 (BRASIL). Com isso, os imigrantes têm garantidos os direitos elencados na lei. Esses direitos consistem em:

Art. 40 Ao migrante é garantida no território nacional, em condição de igualdade com os nacionais, a inviolabilidade do direito à vida, à liberdade, à igualdade, à segurança e à propriedade, bem como são assegurados: I - direitos e liberdades civis, sociais, culturais e econômicos; II - direito à liberdade de circulação em território nacional; III - direito à reunião familiar do migrante com seu cônjuge ou companheiro e seus filhos, familiares e dependentes; IV - medidas de proteção a vítimas e testemunhas de crimes e de violações de direitos; $V$ - direito de transferir recursos decorrentes de sua renda e economias pessoais a outro país, observada a legislação aplicável; VI - direito de reunião para fins pacíficos; VII - direito de associação, inclusive sindical, para fins lícitos; VIII - acesso a serviços públicos de saúde e de assistência social e à previdência social, nos termos da lei, sem discriminação em razão da nacionalidade e da condição migratória; IX - amplo acesso à justiça e à assistência jurídica integral gratuita aos que comprovarem insuficiência de recursos; $\mathrm{X}$ - direito à educação pública, vedada a discriminação em razão da nacionalidade e da condição migratória; XI - garantia de cumprimento de obrigações legais e contratuais trabalhistas e de aplicação das normas de proteção ao trabalhador, sem discriminação 
em razão da nacionalidade e da condição migratória; XII - isenção das taxas de que trata esta Lei, mediante declaração de hipossuficiência econômica, na forma de regulamento; XIII - direito de acesso à informação e garantia de confidencialidade quanto aos dados pessoais do migrante, nos termos da Lei no 12.527, de 18 de novembro de 2011; XIV direito a abertura de conta bancária; XV - direito de sair, de permanecer e de reingressar em território nacional, mesmo enquanto pendente pedido de autorização de residência, de prorrogação de estada ou de transformação de visto em autorização de residência; e $X V I$ - direito do imigrante de ser informado sobre as garantias que lhe são asseguradas para fins de regularização migratória. § 10 Os direitos e as garantias previstos nesta Lei serão exercidos em observância ao disposto na Constituição Federal, independentemente da situação migratória, observado o disposto no $\S 40$ deste artigo, e não excluem outros decorrentes de tratado de que o Brasil seja parte (BRASIL, 2017).

Diante do rol de garantias e direitos apresentados, a inviolabilidade do direito à liberdade, à vida, à igualdade e à propriedade, são direitos igualmente atribuídos aos imigrantes e que necessitam de recursos para a sua implementação. Além do mais, é relevante para a pesquisa proposta, destacar o acesso adequado e digno a serviços públicos de saúde e de assistência social. Esses são basilares para a garantia da dignidade humana tanto do imigrante, como do próprio nacional.

Ao enfatizar o direito acima, é que se faz necessário um estudo concentrado sobre a questão que ocorre na saúde pública da região de RR, pois é exatamente pelo déficit de tal garantia que se observa a grande quantidade de casos confirmados de sarampo, que preocupa a comunidade e as autoridades regionais e nacionais.

\section{SAÚDE PÚBLICA E O SARAMPO NA REGIÃO DE RORAIMA}

O sarampo é uma doença infectocontagiosa grave, transmitida por via respiratória, que tem como agente patogênico, um vírus. A efemeridade acomete comumente crianças, principalmente as enquadradas em situações de desnutrição.

Diversas manifestações clínicas caracterizam o sarampo, dentre elas, perdas de eletrólitos e proteínas. Sintomas comuns são febre, tosse, coriza, conjuntivite e manchas brancas que aparecem na mucosa bucal e a clássica erupção cutânea na pele (BRASIL, 2018d). Casos graves podem levar à pneumonia, cegueira, encefalite e óbito.

Em meados dos anos de 2016, a OPAS/OMS, lançou nota (OPAS, on-line), declarando que a região das Américas se encontrava livre do sarampo. Resultado este, devido a mais de 20 anos de ampla administração da vacina contra a doença no continente.

Em nota ainda, a OPAS/OMS afirma que sem a campanha de vacinação, até os anos de 1980, o sarampo era responsável por mais 2 milhões de mortes anuais no mundo, onde mais de 100.000 óbitos ocorreram nas Américas. Após a vacinação maciça, os países dessa região preveniram mais de 3 milhões de casos da doença entre os anos de 2000 e 2020 (BRASIL, 2018e). 
Em contrapartida, no mês de abril do ano de 2018, onze países das Américas notificaram 385 casos confirmados de sarampo, dentre eles, o Brasil com 46 casos, de acordo com a OPAS (G1, 2018). Esse ressurgimento da doença, se dá devido ao frequente fluxo migratório de populações não imunizadas.

Entretanto, a Secretaria Estadual de Saúde do estado de Roraima, declarou (OPAS, on-line) um dia após lançamento da nota da OPAS, que Roraima passou de surto para epidemia de sarampo. A diferença entre os termos é devido a confirmação de casos em outro estado, o Amazonas (4 casos). Em RR foram confirmados 79 casos, além de duas mortes de crianças venezuelanas na capital, até a data ${ }^{5}$ da coleta de dados da presente pesquisa.

Dentre os casos, 55 são de cidadãos venezuelanos e 24 de brasileiros. Como ação de saúde pública, o Ministério da Saúde em parceria com governos estaduais e municipais e a OPAS/OMS, providenciaram vacinação da população, inclusive dos venezuelanos. A campanha está ocorrendo (março a abril) em praças públicas, postos de saúde, além de um posto de vacinação na fronteira entre estado de Roraima e Venezuela (BRASIL, 2018e).

As medidas protetivas e de combate ao sarampo frente a epidemia, se estabelecem na expectativa de que ocorra a vacinação de pelo menos $95 \%$ da população nacional e imigrante. 0 Ministério da Saúde somado ao Estado de Roraima disponibilizou cerca de 100 mil doses de vacina tríplice viral, que são medidas profiláticas contra sarampo, rubéola e caxumba. A campanha de vacinação nos municípios dos estados de Roraima e Amazonas, compreende imunizar a população com faixa etária de seis meses a 49 anos $^{6}$.

O sarampo não tem tratamento específico, recomenda-se administrações de vitamina A para crianças. O suporte para doença é manter hidratação e boa alimentação. A prevenção é a melhor estratégia profilática do sarampo, a vacina se dá em duas doses na infância.

\section{REAÇÃO DO ESTADO FRENTE A SITUAÇÃO OCASIONADA PELA IMIGRAÇÃO}

Uma onda de acontecimentos na região fronteiriça com a Venezuela e Brasil forçou o governo de Roraima a uma reação, vez que, não consegue lidar com o grande número de imigrantes que lotam as ruas e praças publica, que sufocam a região já frágil diante de uma crise econômica presente em todo o território brasileiro, além de importarem consigo, vírus e doenças infectocontagiosas para o território nacional. Sendo que em RR, as proporções diárias de sujeitos venezuelanos que ingressam no Brasil, ultrapassam a capacidade que o estado tem para atender e prestar serviços a essas pessoas (PUPO; MOURA; NAKAGAWA, 2018).

Para tanto, o governo local ingressou com uma ação civil pública (ACP) no Supremo Tribunal Federal (STF), fundamentando dentro outros pontos, a necessidade de se barrar a entrada de tais imigrantes, propondo um fechamento provisório da fronteira como forma de manter a integridade dos cidadãos nacionais, que se encontram em situação de vulnerabilidade, frente ao aumento maciço da

5 Dados pesquisados no dia 18 de abril, 2018.

6 Disponível em: htps://veja.abril.com.br/saude/oms-emite-alerta-para-surto-de-sarampo-no-brasil/. Acesso em: 18 abr. 2018. 
criminalidade e o surgimento de vírus e doenças advindas do país vizinho, que devido a uma crise econômica e política, não vem conseguindo garantir necessidades básicas aos seus cidadãos, causando uma onda de imigração desses sujeitos, que buscam conseguir oportunidades de emprego e condições dignas de vida em solo brasileiro (PUPO; MOURA; NAKAGAWA, 2018).

Ademais, no pleito protocolado ao STF, argumenta o governo roraimense, que seja viabilizado ao estado, recursos adicionais da União para que o mesmo possa lidar com a alta demanda de serviços públicos que necessitam os cidadãos estrangeiros. Como serviços de saúde e vigilância sanitária, que se mostram como de maior necessidade em virtude dentre outros casos, a epidemia de sarampo na região (MAIA, 2018).

Neste viés, com o surgimento do surto de sarampo na região, fez nascer para o estado, a obrigação de rigoroso controle de entrada desses imigrantes. Pois é sabido que estes estão trazendo consigo o reflexo de uma má gestão pública em saúde de seu país de origem. Gera-se, assim, consequências como a que se vê na região de Roraima, que não presenciava esse tipo de virose desde o ano de 2015. A crescente onda de imigração, fez com que tal epidemia surgisse novamente no cenário nacional, marcada por um cenário desolador de sujeitos buscando o básico para a sua própria subsistência (MARQUES, 2018).

Há com isso, consenso no sentido de afirmar que a imigração é fator preponderante no surgimento de problemas de saúde na população local. Isso motivou a impetração pelo estado de RR de medida judicial para conter o fluxo migratório na região. Conforme disposto pelo estado, a União não estaria prestando a necessária assistência para se conter os problemas da região e que com isso se estaria sufocando a atuação estatal. Resultando na falta de prestação de serviços básicos, diante da escassez de recursos para tamanha proporção de populares estrangeiros que se alocam em locais públicos, como ruas e praças das principais cidades do Estado (PUPO; MOURA; NAKAGAWA, 2018).

Sobre a mesma vertente, é notório o papel da União frente a crise migratória vivenciada. Deve com isso, por força do estabelecido no art. 23, II da Constituição Federal de 1988, prestar a assistência que é necessária à garantia da proteção da saúde da população local (BRASIL, 2018c). Utilizando, para tanto, de recursos financeiros que visem incentivar as políticas públicas de prevenções contra as doenças infectocontagiosas. Sendo este um dos fundamentos que originou a medida judicial proposta pelo estado de RR ao STF, visando justamente garantir a saúde da população local que está a mercê de epidemias vindas do estrangeiro e que, devido à escassez de recursos financeiros próprios, não consegue arcar com os custos excessivos causados pelos cidadãos venezuelanos.

Por fim, a de destacar que situação vivenciada na região se encontra incerta, e o cenário local promete ser palco de muitas incertezas, diante de possibilidade de isolamento ou não da região fronteiriça, a depender do provimento ou não da medida judicial que se encontra no Supremo Tribunal Federal para apreciação. Nestes termos, é importante problematizar se realmente será eficaz o deferimento ou não da medida. Será que a possível decisão de deferimento é suficiente para barrar a entrada de imigrantes? A solução para a situação consiste realmente no fechamento de fronteiras, ou devem-se aplicar recursos que visem recepcionar os imigrantes de maneira digna?

De fato, as respostas para essas indagações só poderão ser sanadas no transcurso deste desfecho. 0 que não deve haver é a negligencia dos entes federados para com a situação que se vivencia na região, que por si necessita de uma atenção especial. 


\section{CONSIDERAÇÕES FINAIS}

O presente trabalho foi de grande relevância, visto que proporcionou a divulgação de informações importantes, como os direitos dos imigrantes no Brasil, prevenção e reposta a epidemia de sarampo com apoio dos entes federativos e organizações mundiais.

Foi possível perceber que o Brasil recepciona imigrantes de forma ética, se preocupa e investe no bem-estar, tanto do nacional fronteiriço como dos imigrantes. Aliado a isso, a União disponibilizou grandes investimentos em vacinas, visando conter a epidemia de sarampo naquela região. Essa medida mostra-se de grande exemplo em âmbito internacional, pois o investimento em políticas públicas de saúde é a melhor forma de proteger a sociedade de mazelas que podem acometer o homem.

Observou os pleitos da ação civil pública de RR, analisando os mesmos, com objetivo de chegar a alguma conclusão sobre o que deveria ser feito no estado para conter a epidemia e se tais pedidos realmente seriam efetivos. Descobriu-se que a melhor medida a ser adotada, seria maiores investimentos na prevenção de doenças, recursos adicionais para moradia, educação, trabalho, entre outras garantias fundamentais e básicas.

Por fim, conclui-se este trabalho, com a satisfação de informar o meio científico, que o país está cumprindo com suas obrigações legais juntamente com a ajuda da OMS. Ambos estão dispostos a solucionar o problema de saúde coletiva daquela região.

\section{REFERÊNCIAS}

BRASIL. Congresso Nacional. Lei n 13.445, de 24 de maio de 2017. Disponível em: http://www. planalto.gov.br/ccivil_03/_ato2015-2018/2017/lei/L13445.htm. Acesso em: 17 abr. 2018a.

BRASIL. Congresso Nacional. Lei no 9.474, de 22 de julho de 1997. Disponível em: http://www. planalto.gov.br/ccivil_03/LEIS/L9474.htm. Acesso em: 17 abr. 2018b.

BRASIL. Congresso Nacional. Constituição da República Federativa do Brasil de 1988. Disponível em: http://www.planalto.gov.br/ccivil_03/constituicao/constituicao.htm. Acesso em: 17 abr. 2018c.

BRASIL. Ministério da Saúde. Sarampo. Disponível em: http://portalms.saude.gov.br/saude-de-a-z/ sarampo. Acesso em: 18 abr. 2018d.

BRASIL. Organização Pan-americana da Saúde. Região das Américas registra casos de sarampo em 11 países. Disponível em: http://www.paho.org/bra/index.php?option=com_content\&view=art icleqid=5629:regiao-das-americas-registra-casos-de-sarampo-em-11-paises\&ltemid=820. Acesso em: 18 abr. 2018e. 
G1. Saúde declara epidemia de sarampo em Roraima após casos suspeitos da doença em 10 cidades. Globo.com. 10 abr. 2018. Disponível em: https://g1.globo.com/rr/roraima/noticia/saudedeclara-epidemia-de-sarampo-em-roraima-apos-casos-suspeitos-da-doenca-em-10-cidades.ghtml. Acesso em: 18 abr. 2018.

\section{MAIA, Mateus. Roraima vai pedir ao STF que união feche provisoriamente fronteira com}

Venezuela até haver controle melhor. 2018. Disponível em: https://br.reuters.com/article/ topNews/idBRKBN1HK2IY-OBRTP. Acesso em: 17 abr. 2018.

MARQUES, Marcelo. Roraima declara surto de sarampo no estado e antecipa campanha de vacinação. 2018. Disponível em: https://oglobo.globo.com/brasil/roraima-declara-surto-de-sarampo-no-estadoantecipa-campanha-de-vacinacao-22457533\#ixzz5Cwkp346v. Acesso em: 17 abr. 2018.

OPAS - Organização Pan-Americana da Saúde. Região das Américas é declarada livre de sarampo. OPAS Brasil. Disponível em: http://www.paho.org/bra/index.php?option=com_content\&view=article \&id=5248:regiao-das-americas-e-declarada-livre-de-sarampo\&ltemid=82. Acesso em: 18 abr. 2018.

OPAS - Organização Pan-Americana da Saúde. Região das Américas registra casos de sarampo em 11 países. OPAS Brasil. Disponível em: https://www.paho.org/bra/index.php?option=com_content\& view=article\&id=5629:regiao-das-americas-registra-casos-de-sarampo-em-11-paises\&ltemid=820. Acesso em: 18 abr. 2018.

PUPO, Amanda; MOURA, Rafael Moraes; NAKAGAWA, Fernando. Roraima quer que união feche fronteira entre Brasil e Venezuela. 2018. Disponível em: http://brasil.estadao.com.br/ noticias/geral,roraima-entra-com-acao-no-stf-para-que-uniao-feche-fronteira-entre-brasil-evenezuela,70002267272. Acesso em: 17 abr. 2018. 
1 Acadêmico do último ano de Direito do Centro Universitário Tocantinense Presidente Antônio Carlos (UNITPAC). Monitor de Direito Tributário UNITPAC.

E-mail: jayrtonnoleto@outlook.com.

2 Graduado em Direito pelo Centro Universitário Tocantinense Presidente Antônio Carlos (UNITPAC). Pós-graduando em Direito do Trabalho e Departamento Pessoal. E-mail: osvaldovanderley@hotmail.com

3 Mestranda em Sanidade Animal e Saúde Pública nos Trópicos (PPGSaspt) pela UFT. Especialista em Docência no Ensino Superior pela Universidade Cândido Mendes. Licenciada em Biologia pela UFT. Professora Substituta do Colegiado de Biologia da Universidade Federal do Tocantins (UFT). E-mail: hmbiazussi@hotmail.com.

4 Doutor em letras (Estudos Linguísticos) pela Universidade Federal do Tocantins (UFT). Professor do Centro Universitário Tocantinense Presidente Antônio Carlos (UNTPAC). E-mail: brunogomespereira_30@hotmail.com

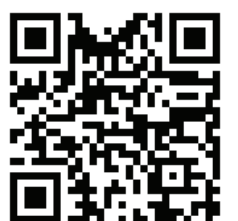

A autenticidade desse artigo pode ser conferida no site https://periodicos. set.edu.br

\section{Como citar este artigo:}

DE MACEDO, Jayrton Noleto. VENEZUELANOS NO BRASIL: DIREITOS DOS IMIGRANTES E A SAÚDE PÚBLICA LOCAL. Interfaces Científicas Direito, Aracaju, v. 7, n. 2, p. 75-84, abr.mai/jun. 2019. DOI: $10.4025 /$ actascieduc.v41i1.34184. Acesso em: 24 mar. 2019.

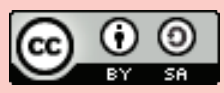

Este artigo é licenciado na modalidade acesso abertosob a Atribuição-Compartilhalgual CC BY-SA

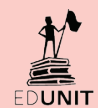

